\title{
Multijunction solar cells incorporating Group IV SiGeSn alloys
}

Pablo Caño, Iván Lombardero, Ignacio Rey-Stolle

\author{
Andrew Johnson, Rick Hoffman Jr
}

\begin{abstract}
In order to get higher efficiencies in multijunction solar cells, a $1 \mathrm{eV}$ material lattice matched to germanium has been searched tenaciously for years. In this context, a hybrid III-V/IV multijunction and single junction solar cells incorporating $1 \mathrm{eV}$ SiGeSn alloy are presented. A basic characterization of these solar cells, which has been grown by CVD and subsequent MOCVD, has been carried out.
\end{abstract}

Keywords-Multijunction solar cells; SiGeSn; Group IV; $1 \mathrm{eV}$

\section{INTRODUCTION}

Over the last 15 years, the III-V multijunction solar cell field has been dominated by the triple-junction $\mathrm{GaInP} / \mathrm{Ga}(\mathrm{In}) \mathrm{As} / \mathrm{Ge}$ solar cell. This design has been the workhorse for space power applications since the early 2000's and, as a result of that, made its way into CPV technology were it has been extensively used too [1]. As of 2016, this configuration is still the standard commercial product offered by many companies in the field. The keys to the success of this solar cell have been its high efficiency, reliability and radiation hardness. These features stem from the fact that the top GaInP and middle $\mathrm{Ga}(\mathrm{In}) \mathrm{As}$ solar cells are high quality devices epitaxialy grown lattice matched to a germanium substrate. However, it is well known that the bandgap combination in this device is not optimum -the bandgap of Ge is too low- and the room for improvement is almost exhausted. It has been recurrently shown that adding a $1.0 \mathrm{eV}$ material between the $1.4 \mathrm{eV} \mathrm{Ga}(\mathrm{In})$ As and the $0.67 \mathrm{eV} \mathrm{Ge}$, could thrust efficiencies up to $32 \%$ for space applications and close to $50 \%$ for concentrator applications [1]. As a result of this, the search for this lattice matched $1.0 \mathrm{eV}$ material has been intense over the last years, with limited success though [2]. Dilute nitride GaInNAsSb alloys have produced some success in triple junction configurations, namely, when grown on GaAs, but their growth on Ge substrates seems elusive. Metamorphic layers [3] or mechanical stack have been an alternative path to implement this leV subcell, although their development is still in progress.

In this context, group IV SiGeSn alloys were proposed as a possible candidate for this $1.0 \mathrm{eV}$ junction [4]. Figure 1 shows the band gap of the binary semiconductors $\mathrm{Si}_{\mathrm{x}} \mathrm{Ge}_{1-\mathrm{x}}, \mathrm{Si}_{\mathrm{y}} \mathrm{Sn}_{1-\mathrm{y}}$ and $\mathrm{Ge}_{\mathrm{z}} \mathrm{Sn}_{1-\mathrm{z}}$ versus lattice constant. As this figure shows with a red line, compositions lattice-matched to
Ge can be obtained sweeping a bandgap range from $0.67 \mathrm{eV}$ (i.e. pure $\mathrm{Ge}$ ) to $1.1 \mathrm{eV}\left(\mathrm{Si}_{0.8} \mathrm{Sn}_{0.2}\right)$, with the $1.0 \mathrm{eV}$ alloy having a composition of $\mathrm{Ge}_{0.875} \mathrm{Si}_{0.11} \mathrm{Sn}_{0.025}$ [4].

Despite the development of this new alloy is still in its infancy, materials research is progressing and the first prototypes of operating devices have been reported [5]. Here, the characterization of a set of single and multijunction solar cells incorporating SiGeSn active junctions is presented.

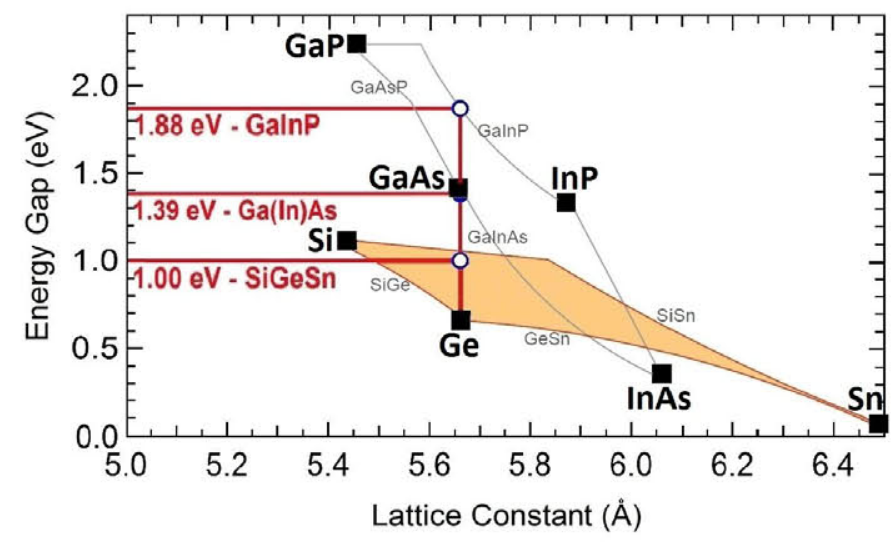

Figure 1. Calculated bandgap of the binary semiconductors $\mathrm{Si}_{\mathrm{x}} \mathrm{Ge}_{1-\mathrm{x}}, \mathrm{Si}_{\mathrm{y}} \mathrm{Sn}_{1-\mathrm{y}}$ and $\mathrm{Ge}_{2} \mathrm{Sn}_{1-z}$ versus lattice constant. The composition that has a bandgap of $1.0 \mathrm{eV}$ is marked with the lower blue circle and is $\mathrm{Ge}_{0.875} \mathrm{Si}_{0.11} \mathrm{Sn}_{0.025}$. The vertical red line represents compounds lattice matched to Ge. Band gaps of the III-V semiconductors are represented with the red lines.

\section{EXPERIMENTAL}

Single junction and multijunction solar cell structures were grown following a combined approach using chemical vapor deposition and metal-organic vapor phase epitaxy. Initially, the $\mathrm{SiGeSn}$ alloys were grown with an ultra-high vacuum CVD on 4-inch Ge (100) substrates, with a miscut of $6^{\circ}$ towards the $<111>$ plane to reduce the formation of anti-phase boundaries in the subsequent MOCVD growth [6]. Before the $1.0 \mathrm{eV}$ SiGeSn layer, a highly doped SiGeSn acting as back surface field was grown in order to limit the diffusion of minority carriers into the Ge inactive substrate [5]. The SiGeSn subcell was p-type doped to $1 \times 10^{18} \mathrm{~cm}^{-3}$. Subsequent growth of the IIIV subcells was carried out in a MOVPE reactor using standard precursors. Following this approach two types of devices were 
grown, namely, single junction SiGeSn cells and triple junction $\mathrm{GaInP} / \mathrm{Ga}(\mathrm{In}) \mathrm{As} / \mathrm{SiGeSn}$ solar cells. In both cases the $\mathrm{Ge}$ substrate was kept inactive since the tunnel junction between the $\mathrm{SiGeSn}$ and the Ge subcell has not been engineered yet. The configuration of the $\mathrm{SiGeSn}$ and the $\mathrm{GaInP} / \mathrm{Ga}(\mathrm{In}) \mathrm{As} / \mathrm{SiGeSn}$ can be seen in Figure 2. Both the single-junction and triple-junction epiwafers were processed into $1 \mathrm{~cm}^{2}$ solar cells using conventional photolithographic techniques and physical vapor deposition for the metal contacts.
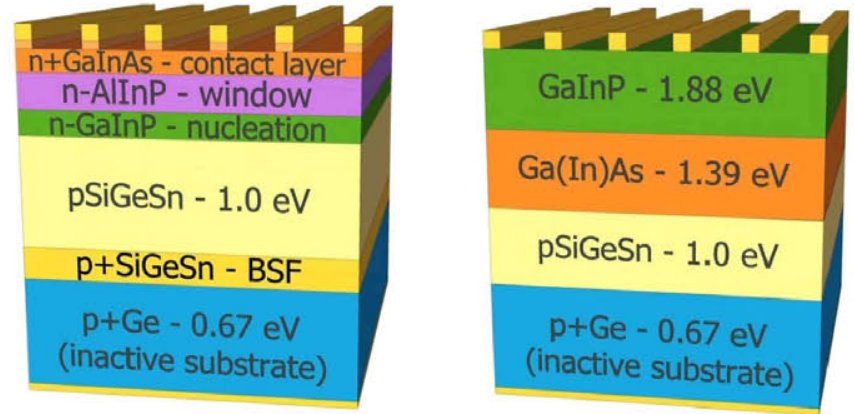

Figure 2. Structures of the solar cells characterized. (Left) Structure grown for the SiGeSn solar cell; (Right) Structure of the 3 junction solar cell: $\mathrm{GaInP} / \mathrm{Ga}$ (In)As/SiGeSn.

\section{Characterization AND RESUTLS}

A characterization of these new devices has been carried out. Regarding the single-junction solar cell, external quantum efficiency was measured for all the devices in the wafer (52) in order to study the dispersion in the results and thus examine the growth homogeneity. These measurements are depicted in Figure 3 and, as it can be observed, the dispersion between the different solar cells is low. Thus, we can conclude that both optical thickness and collection efficiency (i.e. minority carrier parameters) are maintained similar across the wafer. On the other hand, it is observable that there is a response over 1240 $\mathrm{nm}$, which is $1.0 \mathrm{eV}$. This means that the band gap of this alloy is not the target $1.0 \mathrm{eV}$ but it is lower. The linear extrapolation of the EQE from 1300 to $1360 \mathrm{~nm}$ gives an estimate for a direct transition at $\sim 0.88 \mathrm{eV}$ for this cell. Since the EQE clearly extends further down in the IR with a much weaker absorption, there must be an even lower indirect bandgap, possibly due to the lack of sufficient $\mathrm{Sn}$ being incorporated into the alloy. This is currently under investigation.

Furthermore, I-V curves under one sun (Figure 4) and in dark conditions (Figure 5) were measured. The dispersion in curves is again low, except for some devices exhibiting localized shunts due to isolated defects. The open-circuit voltage, $\mathrm{V}_{\mathrm{OC}}$, is lower than expected -in agreement with a lower bandgap as measured in EQE-, and the short-circuit current, $\mathrm{I}_{\mathrm{SC}}$, is also moderate. Anyhow, their values, together with the Fill Factors', are similar for all the solar cells measured. On the other hand, the dark current is dominated by $\mathrm{J}_{02}$, which means that the main recombination processes are taking place in the space charge region. In spite of this modest $\mathrm{I}-\mathrm{V}$ curves, these measurements corroborate the homogeneity among devices observed in the external quantum efficiency. In addition, these results demonstrate that functional photovoltaic action in this new material has been achieved with reasonable performance, which is quite promising.

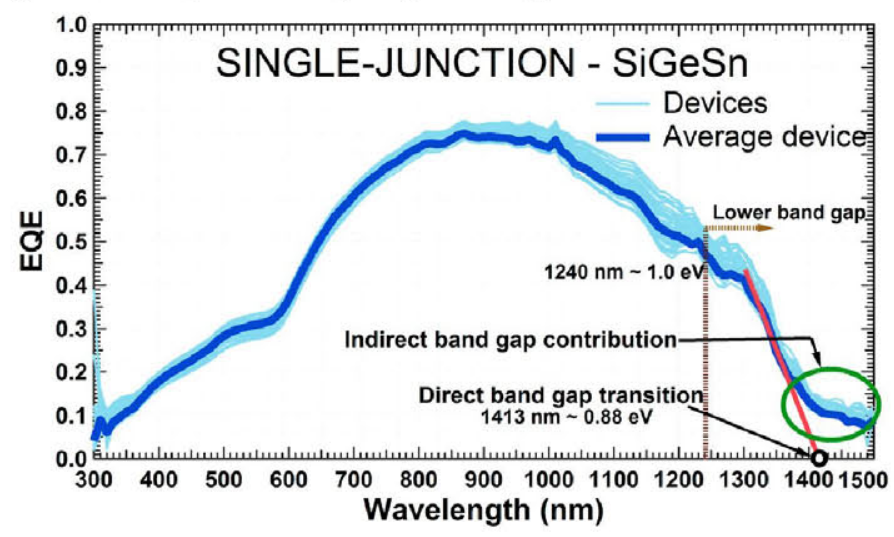

Figure 3. EQE of the SiGeSn single-junction solar cells within the wafer. EQE in dark blue indicates the average device.

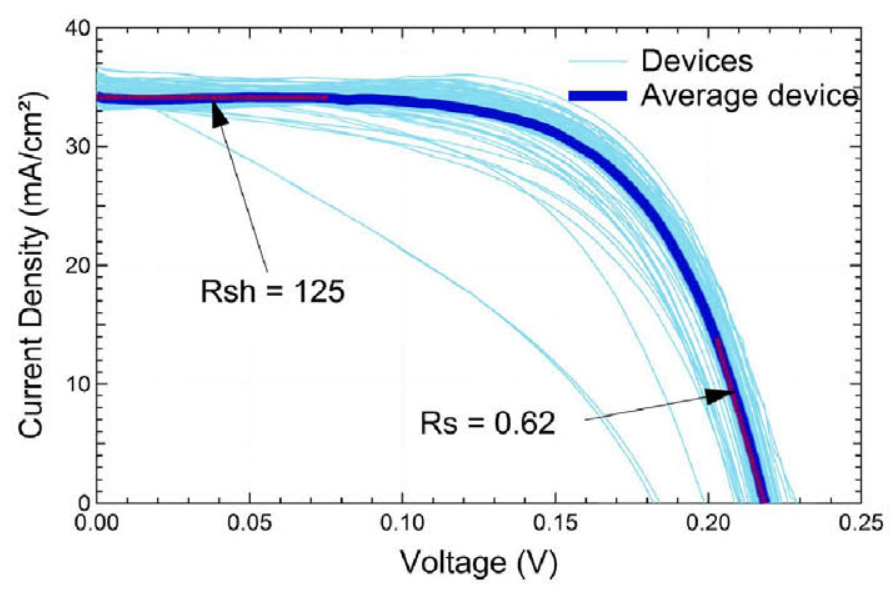

Figure 4. I-V curves of the solar cells grown on the wafer under one sun. I-V curve in dark blue indicates an average device.

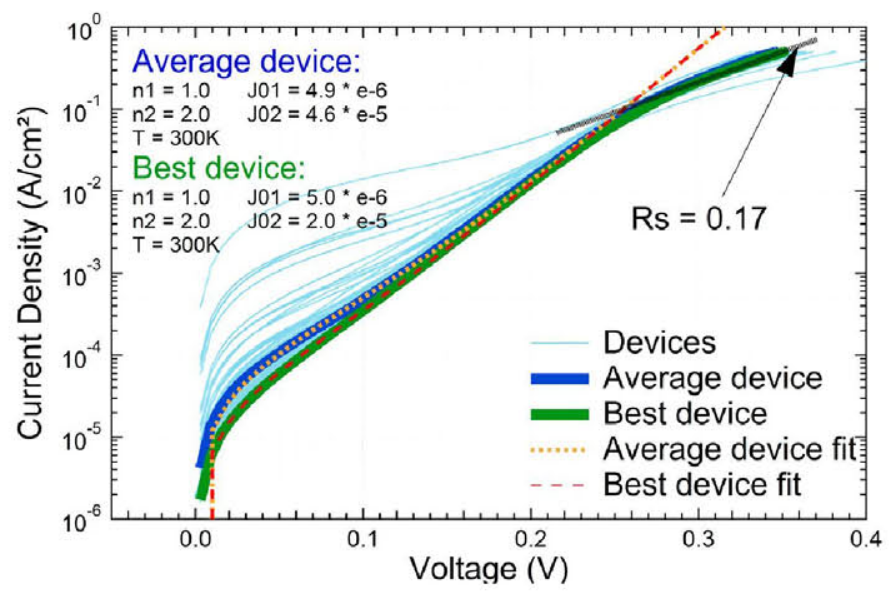

Figure $5 \mathrm{I}-\mathrm{V}$ curves of the solar cells grown on the wafer under dark conditions. Dark blue curve indicates an average device, whereas green curve shows one of the best device achieved. Parameters, as the reverse saturation current density and ideality factors, have been calculated [7][8]. 
Similar SiGeSn material was used to implement the bottom cell of triple junction solar cells (Figure 2, right). The I-V curves under dark conditions for this triple junctions have been measured for all the solar cells in the wafer ( 52 devices). As Figure 6 shows, the dark I-V curves present a large dispersion between devices, whereas the wafer map included as an inset discloses that the growth has been inhomogeneous, being the solar cells with similar shunt resistance gathering in concentric regions. The worse devices (red) are located in the center of the wafer and shunt resistance decreases as we move away from this center, being the best solar cells (green) situated at the left edge of the wafer.

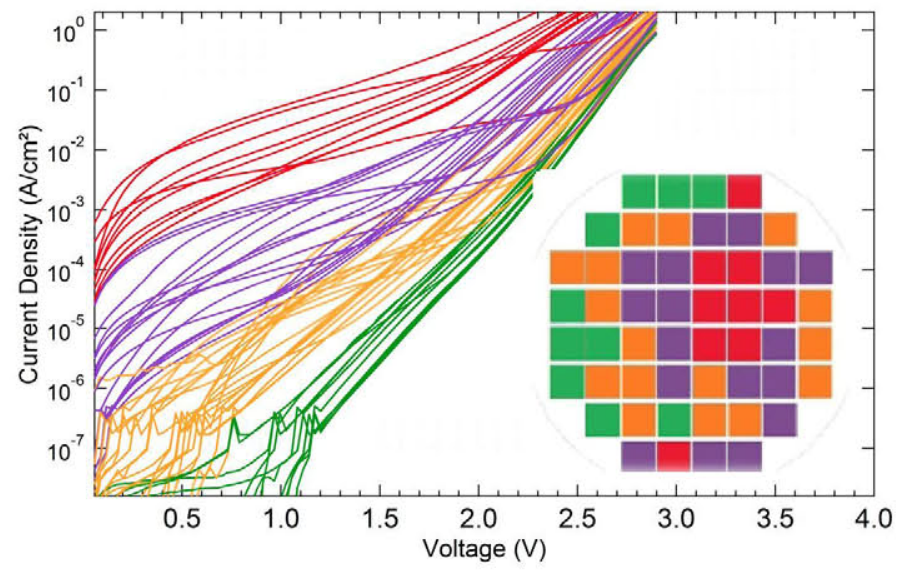

Figure 6. Dark I-V curves of the multijunction solar cells and a map of the wafer which classifies them according to the shunt resistance they present.

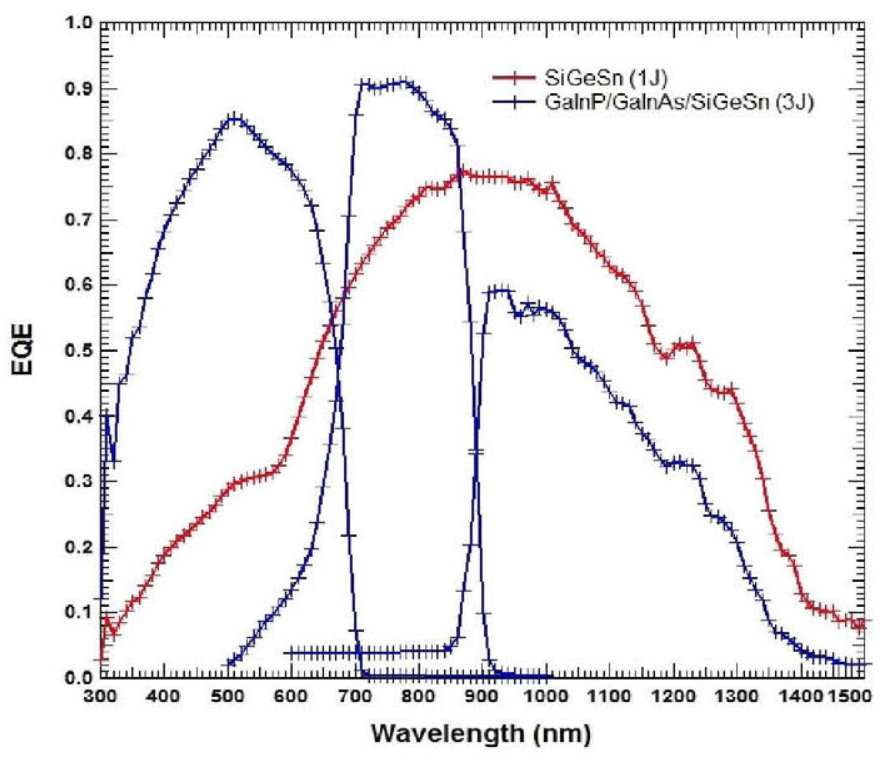

Figure 7. $\mathrm{EQE}$ of the $\mathrm{SiGeSn}$ single junction (in red) and the triple junction solar cell (in blue).

External quantum efficiency was also measured for these multi-junction solar cells, as shown in Figure 7. As it can be observed, EQE of the top cell and middle cell are apparently acceptable, which means that, even though SiGeSn alloy is a young material and needs to be enhanced, it is suitable as a template for subsequent III-V semiconductor growth. Therefore, a first conclusion is that the double epi-growth in two reactors has been successfully carried out. However, it is clearly noticeable that the SiGeSn bottom subcell shows a degraded performance. This fact could mean that the subsequent high temperature or diffusion processes, which this SiGeSn has to bear during the III-V growth, affects negatively to this alloy.

\section{CONCLUSIOS AND FUTURE WORKS}

In the search to develop a $1.0 \mathrm{eV}$ subcell, which can improve the widespread triple junction $\mathrm{GaInP} / \mathrm{Ga}(\mathrm{In}) \mathrm{As} / \mathrm{Ge}$ solar cell, group IV SiGeSn alloys have been investigated. Single-junction $\mathrm{SiGeSn}$ and triple-junction $\mathrm{GaInP} / \mathrm{Ga}(\mathrm{In}) \mathrm{As} / \mathrm{SiGeSn}$ cells have been manufactured and characterized. Both single and multi-junction solar cells have been grown throughout CVD and subsequent MOVPE. A complete characterization has been carried out afterwards. These experiments have revealed that the SiGeSn solar cell has a promising homogeneous growth exhibiting moderate features, as a reasonable quantum efficiency. As for the triplejunction solar cell, despite the top cell and middle cell present a good quantum efficiency making the SiGeSn alloy capable of subsequent III-V growth, the bottom cell shows degradation during MOVPE process. Moreover, the sweep carried out on the wafer displays an inhomogeneous growth making this process unfeasible for industrial applications thus far.

For making this new material usable in subcells being part of new generations of multi-junction solar cells, an enhancement of the SiGeSn alloy has to be performed, due to the inhomogeneous growth presented by the triple-junction solar cell. For future works, a full implementation of this multijunction solar cell could be carried out through the replacement of the expensive Ge substrate for a silicon inactive substrate, which would need a metamorphic SiGeSn layer in order to grow lattice match to the silicon substrate.

\section{REFERENCES}

[1] C. Algora and I. Rey-Stolle, Handbook of Concentrator Photovoltaic Technology, Wiley (2016)

[2] M. Wiemer, V. Sabnis and H. Yuen, "43.5\% efficient lattice matched solar cells", Proc. SPIE 8108 (2011)

[3] R. M. France, F. Dimroth, T. J. Grassman, R. King, "Metamorphic epitaxy for multijunction solar cells", MRS Bulletin, 41(3), 202-209 (2016)

[4] R. Soref, C. Perry, "Predicted band gap of the new semiconductor SiGeSn", J. Applied Physics 69, 539 (1991)

[5] R. Roucka et al., "Demonstrating Dilute-Tin Alloy SiGeSn for Use in Multijunction Photovoltaics: Single- and Multijunction Solar Cells with a 1.0-eV SiGeSn Junction", IEEE Journal of Photovoltaics, Vol. 6, No. 4, pp. 1025 (2016)

[6] T. Wilson et al., "Single and multi-juntion solar cells utilizing a $1.0 \mathrm{eV}$ SiGeSn junction", AIP Conference Proceedings (2016)

[7] D. Pysch, A. Mette and S.W. Glunz, "A review and comparison of different methods to determine the series resistance of solar cells", Solar Energy Materials \& Solar Cells 91 (2007)

[8] P. Singh and N.M. Ravindra, "Analysis of series and shunt resistance in silicon solar cells using single and double exponential models", Emerging Materials Research, Vol. 1 (2012) 